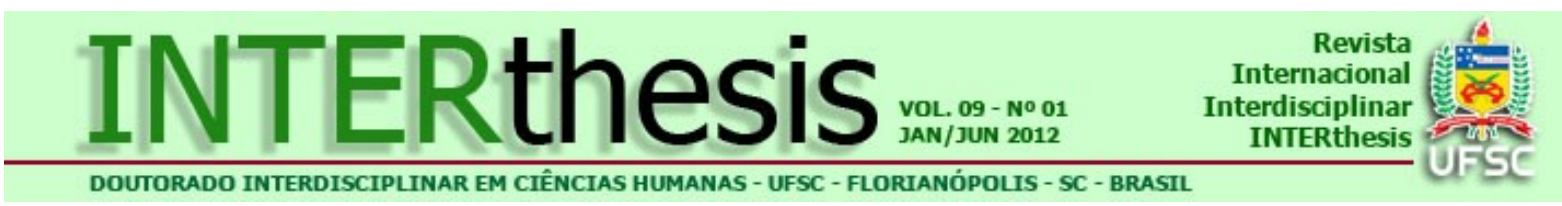

\title{
O “NOVO” DIREITO À ÀGUA NO CONSTITUCIONALISMO DA AMÉRICA LATINA
}

THE "NEW" RIGHT TO WATER IN THE LATIN-AMERICAN
CONSTITUTIONALISM

\section{EL “NUEVO” DERECHO AL AGUA EN EL CONSTITUCIONALISMO DE AMÉRICA LATINA}

\author{
Antonio Carlos Wolkmer ${ }^{1}$ \\ Sergio Augustin ${ }^{2}$ \\ Maria de Fátima S. Wolkmer ${ }^{3}$
}

\section{RESUMO:}

O presente artigo analisa alguns elementos da cosmovisão andina que deram origem ao Novo Constitucionalismo Latinoamericano, notadamente o direito à água. Nessa nova cultura orientada para o Bem Viver, o direito humano aos bens imprescindíveis à manutenção da vida é visto como patrimônio comum projetandose, portanto, este direito a todos os seres vivos bem como para as gerações futuras. Trata-se de uma mudança paradigmática instrumentalizada no marco de algumas constituições, especialmente as da Bolívia e do Equador, tendo como pressuposto a compreensão da comunidade em harmonia, respeito e equilíbrio com a vida, celebrando a Pachamama da qual todos os seres vivos fazem parte. Nessa perspectiva, a partir da Ética Biocêntrica, vinculam o direito à água ao direito à natureza, tendo sua gestão orientada para o Bem Viver. Dessa forma, as mudanças políticas e os novos processos sociais de luta nos Estados latino-americanos engendraram não só novas constituições que materializaram novos atores sociais, realidades plurais e práticas biocêntricas desafiadoras, mas, igualmente, apontam, diante da diversidade de culturas minoritárias, da força inconteste dos povos indígenas do Continente, de políticas de desenvolvimento sustentável e da proteção de recursos comuns naturais, um novo paradigma de constitucionalismo,ou seja,um

\footnotetext{
${ }^{1}$ Professor Titular dos cursos de Graduação e Pós-graduação em Direito da UFSC. Doutor em Direito e Pesquisador PQ 1 do CNPq. Professor Visitante de Cursos de Pós-Graduação em várias universidades do Brasil e do exterior. E-mail: wolkmer@yahoo.com.br

${ }^{2}$ Professor e Coordenador do Programa de Pós-Graduação em Direito Ambiental da Universidade de Caxias do Sul. Doutor em Direito e Magistrado. Pesquisador do projeto Rede Guarani/Serra Geral. Email: augus@terra.com.br

${ }^{3}$ Professora da Faculdade de Direito da Universidade de Caxias do Sul. Doutora em Direito pela UFSC. Pesquisadora do projeto Água, Direito Humano à Água Potável e ao Saneamento Básico nos Países da Unasul/CNPq, e do projeto Rede Guarani/Serra Geral. E-mail: mfwolkmer@yahoo.com.br
}

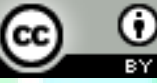
Esta obra foi licenciada com uma Licença Creative Commons - Atribuição 3.0 Não Adaptada. 
Constitucionalismo Pluralista - síntese de um Constitucionalismo indígena, autóctone e mestiço.

Palavras-chave: Novo Constitucionalismo. Bem Viver. Direito Humano à Água. Ética Biocêntrica. Povos Indígenas.

\section{ABSTRACT:}

The article analyses some elements of the Andean cosmovision that originated the New Latin-American Constitutionalism, and specially, the right to the water. In this new culture, oriented to the Buen Vivir (well living), the human right to the goods indispensable to the life is seen as a common inheritance, hence projecting itself to all living creatures, as well as to the future generations. This understanding represents a paradigmatic change already present in some Constitutions, as from Bolivia and Equator, assuming the understanding of the community in harmony, respect and equilibrium with life, celebrating the Pachamama (Mother Earth) from which all the living creatures are a part. In this perspective, having the Biocentric Ethics as a fundament, they bound the right to water to the right to the nature, orienting its management to the Buen Vivir. In this context, the political changes and the new social processes of fighting in the Latina-American States gave birth not only to new Constitutions, resulting in new social actors, plural realities and challenging biocentric practices, but, equally, considering the diversity of the cultures from the minorities, the uncontested strength from the indigenous peoples from the continent, the sustainable development policies and the protection of the natural common resources, point to a new constitutionalist paradigm, a Pluralistic Constitutionalism synthesis of an indigenous, autochthonous, hybrid Constitutionalism.

Keywords: New Constitutionalism. Buen Vivir. Human Right to Water. Biocentric Ethics. Indigenous People.

\section{RESUMEN:}

El presente artículo analiza algunos elementos de la cosmovisión andina que dieron origen al Nuevo Constitucionalismo Latinoamericano, específicamente el derecho al agua. En esta nueva cultura orientada para el Buen Vivir, el derecho humano a los bienes imprescindibles para el mantenimiento de la vida es visto como patrimonio común proyectándose, por tanto, este derecho a todos los seres vivos y a las futuras generaciones. Se trata de un cambio paradigmático instrumentalizado en el marco de algunas constituciones, especialmente las de Bolivia y Ecuador, teniendo como presupuesto la comprensión de la comunidad en armonía, respeto y equilibrio con la vida, celebrando a la Pachamama de la cual todos los seres vivos forman parte. En esta perspectiva, a partir de la Ética Biocéntrica, vinculan el derecho al agua al derecho a la naturaleza, teniendo su gestión orientada hacia el Buen Vivir. De esta forma, los cambios políticos y los nuevos procesos sociales de lucha en los Estados latinoamericanos no solamente engendraron constituciones que materializaron nuevos actores sociales, realidades plurales y prácticas biocéntricas desafiadoras, sino que también apuntan - frente a la diversidad de culturas minoritarias, a la fuerza incontestable de los pueblos indígenas del Continente, a políticas de desarrollo sostenible y a la protección de los recursos comunes naturales - a un nuevo paradigma de constitucionalismo, o sea, un Constitucionalismo Pluralista - síntesis de un Constitucionalismo indígena, autóctono y mestizo.

Palabras clave: Nuevo Constitucionalismo. Buen Vivir. Derecho Humano al Agua. Ética Biocéntrica. Pueblos Indígenas. 


\section{INTRODUÇÃO}

Nas últimas décadas, em um cenário mundializado, marcado pela globalização neoliberal, pelo capitalismo flexível e pela retórica intelectualizada da Pós-Modernidade, bem como pela emergência de lutas, reivindicações e propostas desencadeadas por novos atores coletivos, tem ocorrido processos que permitem construir novos paradigmas, impulsionadores de mudanças radicais na direção de sociedades mais justas, igualitárias e solidárias, capazes de gerar alternativas desde sua própria diversidade, pluralidade e especificidade.

A chamada crise paradigmática cultural, social e política vivenciada pela modernidade chega também aos espaços periféricos e pós-coloniais, como os da América Latina. A crise dominada por contradições internas e profundos conflitos abre espaço para estratégias não só institucionalizadas (via Estado), mas, sobretudo, práticas de ação social e coletiva, processos que se constroem no desenvolvimento, tornando-se sujeitos das mudanças paradigmáticas.

Trabalhar por uma nova cultura, ainda que tenha em conta os parâmetros convencionais do Estado, Mercado e Sociedade Civil, implica em ir mais além, incorporando a natureza e sua preservação como bem mais precioso. Uma nova cultura que harmonize a Vida Humana com a natureza, compartilhando princípios, estratégias e "novos" Direitos. Nessa nova cultura orientada para o "bem viver", é essencial e irrenunciável um "novo" Direito, o Direito Humano aos bens enquanto patrimônio comum. Ora, no cenário mundial, a ONU reconheceu, em 28/07/2010, a água potável e o saneamento básico como um Direito Humano fundamental, em duas históricas Resoluções. Em tal horizonte, complexo e fundamental, a questão dos recursos naturais como patrimônio comum na América Latina compreende um gerenciamento ambiental não tecnocrático (via estatismo ou ordem privada), mas comunitário, participativo e plural. A proposta, aqui, é trazer para a pauta e destacar o desafio ético da importância dos recursos naturais (como a água) enquanto "novo" Direito, um Direito Humano construído não mais de "cima para baixo", mas por estratégias "desde baixo", ou seja, desde a comunidade em sintonia com a sustentabilidade da natureza. Na verdade, trata-se de uma ruptura paradigmática, de projetar uma nova cosmovisão. 
Essa cosmovisão contra-hegemônica vem sendo projetada em nível teórico e em nível prático pelas experiências recentes da cultura social, política e jurídica dos Andes Latino-Americanos, mais especificamente pelos modelos desenhados e oficializados nos Estados da América Latina, dentre os quais, Equador e Bolívia. Trata-se de horizontes inovadores e privilegiados que poderão oferecer subsídios para se repensar a temática de um "novo" Direito, um Direito Humano aos recursos naturais como patrimônio comum, destacando a água, quer seja subterrânea, quer seja superficial, no âmbito mais abrangente da América Latina, e mais específico dos países andinos e do sul do continente.

É com esse propósito que importa trazer e sublinhar alguns elementos institucionalizados nas recentes Constituições do Equador, de 2008, e da Bolívia, de 2009. Tal ilustração será, agora, desenvolvida epistemologicamente nos marcos teóricos do pluralismo jurídico e, metodologicamente, na instrumentalidade prática de Constituições Latino-Americanas, compreendendo, em um nível mais abrangente, o chamado fenômeno político-jurídico do "Novo" Constitucionalismo.

\section{TRADIÇÃO CONSTITUCIONALISTA LATINO-AMERICANO: AUSÊNCIA DE DIREITOS AOS RECURSOS NATURAIS E À ÁGUA}

É significativo que, na América Latina, tanto a cultura sociopolítica imposta pelas Metrópoles ao longo do período colonial, quanto as instituições jurídicas formadas após o processo de independência (tribunais, codificações e constituições) derivam da tradição europeia, representada pelo modelo de Estado e de democracia representativa, bem como pelas fontes clássicas do Direito em sua matriz romana, germânica e canônica. Ora, na formação do sistema de legalidade e do processo de constitucionalização latino-americano pós-independência, há de se ter em conta a herança das cartas políticas burguesas e dos princípios iluministas inerentes às declarações de direitos, bem como o legado proveniente da modernidade capitalista de livre mercado, pautada na tolerância e no perfil liberal-individualista. Nesse sentido, a incorporação do modo de produção capitalista e a inserção do liberalismo individualista tiveram uma função importante no processo de positivação do Direito estatal das antigas colônias ibéricas. Cabe reconhecer que o individualismo liberal e o ideário iluminista dos Direitos do Homem penetraram na América luso-hispânica, no século XIX, dentro de sociedades fundamentalmente agrárias e, em alguns 
casos, escravagistas, em que o desenvolvimento urbano e industrial era praticamente nulo. Desse modo, a juridicidade moderna de corte liberal vai repercutir diretamente sobre as estruturas institucionais dependentes e reprodutoras dos interesses coloniais das metrópoles. ${ }^{4}$

Tem sido próprio na tradição latino-americana, seja na evolução teórica, seja na institucionalização formal do Direito, que as constituições políticas acabaram consagrando, abstratamente, igualdade formal perante à lei, independência de poderes, soberania popular, garantia liberal de direitos, cidadania culturalmente homogênea e a condição idealizada de um "Estado de Direito" universal. Na prática, as instituições jurídicas são marcadas por controle centralizado e burocrático do poder oficial; formas de democracia excludente; sistema representativo clientelista; experiências de participação elitista; e por ausências históricas das grandes massas populares. Certamente, os documentos legais e os textos constitucionais elaborados na América Latina, em grande parte, têm sido a expressão da vontade e do interesse de setores das elites hegemônicas, formadas e influenciadas pela cultura europeia ou anglo-americana. ${ }^{5}$ Poucas vezes, na história da região, as constituições liberais e a doutrina clássica do constitucionalismo político reproduziram, rigorosamente, as necessidades de seus segmentos sociais majoritários, como as nações indígenas, as populações afro-americanas, as massas de campesinos agrários e os múltiplos movimentos urbanos. Tampouco nessa tradição individualista contemplaram-se os direitos aos recursos naturais como patrimônio comum e/ou os direitos do ser humano em sintonia com a natureza.

Esse cenário periférico e continental tem sofrido mudanças com a inserção de nova cosmovisão trazida pela valorização do mundo indígena. Assim, os movimentos políticos insurgentes

ocorridos recentemente em países sul-americanos (Venezuela, Equador e Bolívia) tentam romper com a lógica liberal-individualista das constituições políticas tradicionalmente operadas, reinventando o espaço público a partir dos interesses e necessidades das maiorias alijadas historicamente dos

${ }^{4}$ DE LA TORRE RANGEL, Jesus Antonio. Sociología jurídica y uso alternativo del derecho. México: Instituto Cultural de Aguascalientes, 1997. p. 69-70 e 72-73. Para um maior aprofundamento, consultar: WOLKMER, Antonio Carlos. Síntese de uma história das ideias jurídicas: da Antiguidade clássica à Modernidade. Florianópolis: Fundação Boiteux, 2006. p. 95-97.

${ }^{5}$ Cf. WIARDA, Howard J. O modelo corporativo na América Latina e a latino-americanização dos Estados Unidos. Petrópolis: Vozes, 1983. p. 82, 85-86. Consultar igualmente: CARBONELL, Miguel; OROZCO, Wistano; VAZQUEZ, Rodolfo (Org.). Estado de Derecho. Concepto, fundamentos y democratización em América Latina. México: Siglo Veintiuno, 2002.

R. Inter. Interdisc. INTERthesis, Florianópolis, v.9, n.1, p. 51-69, Jan./Jul. 2012 
processos decisórios. Assim, as novas constituições surgidas no âmbito da América Latina são do ponto de vista da filosofia política e jurídica, uma quebra ou ruptura com a antiga matriz eurocêntrica de pensar o Direito e o Estado para o continente, voltando-se, agora, para refundação das instituições, a transformação das ideias e dos instrumentos jurídicos em favor dos interesses e das culturas encobertas e violentamente apagadas da sua própria história. ${ }^{6}$

Cabe ter em conta, assim, o que vem a ser esse chamado "novo" Constitucionalismo, que está ocorrendo majoritariamente nos países andinos, o qual tem sido a mais recente faceta no estudo do Direito Constitucional, determinando mudanças nas esferas do poder político e na ordem do Estado de Direito, passando a inovar em diversos aspectos, dentre estes a destacada atenção, pela primeira vez, aos "novos" direitos aos bens como patrimônio comum, em que o ponto nodal projeta a questão ao Direito do "bem viver" e o Direito da natureza. Nesse contexto, reconhece-se como um "novo" Direito, o uso e benefício à água potável não só como um patrimônio da sociedade, mas, como um componente essencial da própria natureza.

\section{A FUNDAMENTAÇÃO JURÍDICA DO DIREITO HUMANO À ÁGUA}

O conhecimento que alavanca os processos de mudanças constitucionais, em vários países da América Latina, está fundamentado no paradigma comunitário orientado para o "bem viver". Esse paradigma, adquirido através dos povos indígenas, projeta uma compreensão da comunidade em harmonia, respeito e equilíbrio com todas as formas de vida. Tendo como referente o viver em plenitude, esses povos religam as noções disjuntivas do projeto da modernidade, na medida em que compreendem que na vida tudo está interconectado e é interdependente.

A relação do homem com a natureza no paradigma dominante entende o indivíduo como o único sujeito de direitos e obrigações. Essa concepção redutora, descontextualizada, que elege o indivíduo o único referente, acaba estruturando o sistema jurídico a partir dos direitos exclusivamente individuais. Naturalmente, tendo no mito do desenvolvimento o valor fundamental a partir do modelo capitalista, tal modelo não distribui as riquezas produzidas, aprofundando as desigualdades entre

${ }^{6}$ WOLKMER, Antonio Carlos; FAGUNDES, Lucas Machado. Tendências Contemporâneas do Constitucionalismo Latino-americano: Estado plurinacional e pluralismo jurídico. Pensar. Revista de Ciências Jurídicas. Fortaleza: v.16, n. 02, jul/dez. 2011. 
pessoas e países. Assim, a racionalidade quantificadora que ignora a vida e a diversidade cultural está sendo questionada por visões mais abrangentes e solidárias que tentam frear o processo que está destruindo a Mãe Terra.

Diante da crise multifacetada do "sistema-mundo", que tem no esgotamento e destruição dos ecossistemas seu maior desafio, nasce, então, como resposta, a cultura da vida. No dizer de Mamani,

Todas las culturas tienen una forma de ver, sentir, percibir y proyectar el mundo, al conjunto de estas formas se conoce como Cosmovisión o Visión Cósmica.

Los abuelos y abuelas de los pueblos ancestrales, hicieron florecer la cultura de la vida inspirados en la expresión del multiverso, donde todo está conectado, interrelacionado, nada está fuera, sino por el contrario "todo es parte del todo..."; la armonía y equilibrio de uno y del todo es importante para la comunidad. ${ }^{7}$

A partir desse "novo" marco teórico, as Constituições que compõem o mosaico do novo constitucionalismo na América Latina representam, hoje, uma das vozes mais fortes contra o modelo econômico predatório e excludente que predomina no mundo atual.

Essas constituições, ao partirem de um conceito de cultura da vida expresso no Bem Viver, ultrapassam a perspectiva desenvolvimentista de viver melhor, consumir mais, em detrimento dos outros e da natureza. Como observa Mamani, ideologicamente, isso implica:

1. A reconstituição da identidade cultural da herança ancestral milenar;

2. A recuperação de conhecimentos e saberes antigos;

3. Uma política de soberania e dignidade nacional;

4. A abertura para novas relações de vida comunitária;

5. A recuperação do direito de relação com a Mãe Terra;

6. A substituição da acumulação ilimitada individual do capital pela recuperação Integral do equilíbrio e harmonia com a natureza. ${ }^{8}$

Nesse contexto, a Constituição do Equador de 2008, em nível regional, tornou-se paradigmática, ao declarar o Direito da Natureza, assim como o direito humano à água, como fundamental. A confluência de dois processos foi decisiva para o êxito das propostas inovadoras, na fase de elaboração da nova Constituição.

7 MAMANI, Fernando Huanacuni. Buen Vivir / Vivir Bien: filosofía, políticas, estrategias y experiencias regionales andinas. Lima, Perú, 2010, p.15.

${ }^{8}$ MAMANI, Fernando Huanacuni. Op. cit., p.15.

R. Inter. Interdisc. INTERthesis, Florianópolis, v.9, n.1, p. 51-69, Jan./Jul. 2012 
Por um lado, um longo processo internacional que foi construindo um consenso em torno das questões ambientais e do direito humano à água. Por outro, a cosmovisão andina com o "bem viver", que, frente aos desafios da sustentabilidade ambiental, vem sendo apontada como um modelo alternativo de gestão em harmonia com a vida em todas as suas expressões.

Na perspectiva da cosmovisão andina, o Estado equatoriano passa a assumir um papel estratégico, juntamente com os povos originários e cidadãos, na defesa do patrimônio natural, assim como, na promoção de um modelo de desenvolvimento que reconhece "as raízes milenares, forjadas por mulheres e homens, celebrando a natureza, a Pachamama, da qual somos parte e que é vital para nossa existência". Segundo Mamani, o princípio jurídico ordenador do Direito passa a ser a sabedoria ancestral, projetando um horizonte de "bem viver" centrado na preservação do meio ambiente em todas as suas dimensões. ${ }^{9}$

No processo de elaboração da Constituição do Equador, os debates constituintes em torno das questões fundamentais revelaram um conflito entre duas concepções de desenvolvimento.

Em uma primeira posição, havia os que defendiam ao extremo a visão centrada no mercado, para quem a água é um recurso a mais na produção. Nessa perspectiva, o neoliberalismo, com novas formas de exploração, mobilizou, nas últimas décadas do século passado, os governos da região com um sistema de valores e medidas estruturais, voltadas a atender às necessidades do mercado que foram imposta sistematicamente pelas instituições multilaterais de crédito, como o Banco Mundial. Sob o influxo dessas orientações, iniciou-se a transferência para o setor privado de serviços públicos e comunitários, como os sistemas de água potável e saneamento, bem como a geração de energia através de diferentes modalidades. Assim, parte dos constituintes queriam o aprofundamento $e$ consolidação desse modelo baseado na racionalidade do mercado.

Em posição contrária, havia os constituintes, em harmonia com a cosmovisão andina, que defendiam a água como um direito humano fundamental e a necessidade imperiosa de dar um passo na recuperação do controle estatal e social efetivo sobre a água e a biodiversidade. Para estes, o Estado a partir do Constitucionalismo emancipatório, no seu papel estratégico de condutor dos

\footnotetext{
${ }^{9}$ MAMANI, Fernando Huanacuni. Op. cit., p.12
}

R. Inter. Interdisc. INTERthesis, Florianópolis, v.9, n.1, p. 51-69, Jan./Jul. 2012 
interesses da Pachamama, estaria fundamentado na aliança público/comunitária, projetando-se na construção de uma soberania plural. Na prática seria a superação da lógica do mercado, expressa em todos os setores considerados, em função de sua magnitude, essencial para o desenvolvimento do país. ${ }^{10}$

Nessa disputa de sentido histórico do desenvolvimento entre duas formas de entender a vida, consolidou-se o grupo de constituintes, apoiado pelos diversos movimentos sociais e pela maioria do povo equatoriano, que busca tornar efetivo o sumak kawsay. ${ }^{11}$

Como aponta Acosta no processo constituinte, referente à água, foram aprovados quatro pontos fundamentais: ${ }^{12}$

1. A água é um direito humano;

2. A água é um bem nacional estratégico de uso público;

3. A água é um patrimônio da sociedade;

4. A água é um componente fundamental da natureza, a mesma que tem direitos próprios a existir e manter seus ciclos vitais.

A partir do novo desenho institucional, são estabelecidos critérios de gestão e uso da água em harmonia com a natureza, ultrapassando-se a visão mercantil não só da água como também do meio ambiente.

Essa abordagem complexa não abandona o diálogo intercultural, pelo contrário, vem fortalecida por um amplo movimento em defesa dos direitos humanos em nível internacional, fortalecendo um dos pilares estruturantes da Constituição equatoriana. Nesse sentido, entendem-se os quatro princípios em relação à água, como imperativos na realização dos direitos humanos. A Constituição de 2008 modificou o marco legal para a água na medida em que, segundo Acosta e Martinez:

- Enquanto direito humano, superou-se a visão mercantil da água, instituindo-se como um direito da cidadania, ficando o Estado obrigado a elaborar políticas públicas para tornar efetivo esse direito. ${ }^{13}$ No entanto, o direito humano à água não se restringe ao ser humano, tendo em vista que na cosmovisão andina, a Pachamama é uma totalidade que integra o conjunto dos seres vivos e a natureza.

${ }^{10}$ ACOSTA, Alberto; MARTíNEZ Esperanza. Água: Um derecho humano fundamental. Quito: Abya Yala, 2010. p.18-23.

${ }_{11}^{11}$ Op. cit., p.33

${ }^{12}$ Op. cit., p.19

${ }^{13}$ Op. cit., p.33.

R. Inter. Interdisc. INTERthesis, Florianópolis, v.9, n.1, p. 51-69, Jan./Jul. 2012 
Ora, no sistema internacional de proteção dos direitos humanos, desde a Convenção de Viena em 1992, prevalece o entendimento da realização integral de todos os direitos humanos. Nesse sentido, o direito à água é multidimensional e está intimamente relacionado a uma vida digna.

- Enquanto bem nacional estratégico, tendo como referência o "bem viver", recupera-se as potencialidades do conhecimento ancestral, buscando construir uma governança democrática com instrumentos de gestão, considerados eficientes e amplamente divulgados nos fóruns internacionais da água, como a outorga da água. Da mesma forma, são estabelecidos os princípios da sustentabilidade ambiental, precaução, prevenção e eficiência como critérios para o planejamento de todos os setores considerados estratégicos. No entanto, no contexto da cosmovisão andina, essa tarefa implica enfrentar alguns desafios:

$\rightarrow$ Promover um modelo de Estado que assuma o controle estratégico, garantindo água para todos os setores da sociedade, assim como, para a natureza;

$\rightarrow$ Restaurar conhecimentos tradicionais na promoção de modelos eficientes e justos de gestão que salvaguardem as fontes e os cursos de água, envolvendo diretamente a cidadania, em uma governança democrática.

$\rightarrow$ Superar o modelo disjuntivo e redutor que considera o rio e o mar uma cloaca e reconstruir, a partir da ética do cuidado, uma abordagem complexa para a realização do bem viver.

Segundo a Constituição, no artigo 411: "o Estado garantirá a conservação e o manejo integral dos recursos hídricos, bacias hidrográficas e caudais associados ao ciclo hidrológico. Regulamentará todas as atividades que possam afetar a qualidade e quantidade de água, e o equilíbrio dos ecossistemas, em especial nas fontes e zonas de recarga de água." ${ }^{14}$

- Enquanto patrimônio estratégico: essa é uma das maiores conquistas da Constituição que não vê mais a água como um bem ou um recurso, mas um patrimônio nacional estratégico. A visão patrimonial da água tem como base a harmonia e o equilíbrio que se projetam nas futuras gerações em uma dinâmica que supera a lógica mercantil. Certamente, a categoria de patrimônio estratégico "converte em parte substancial de um novo sistema social e solidário, que reconhece que os seres humanos são o centro e o fim do desenvolvimento em harmonia com a

${ }^{14}$ ACOSTA, Alberto; MARTíNEZ Esperanza. Op. cit., p.191

R. Inter. Interdisc. INTERthesis, Florianópolis, v.9, n.1, p. 51-69, Jan./Jul. 2012 
natureza: sumak kawsay". ${ }^{15}$ Desse modo, sendo a água um patrimônio nacional estratégico, um elemento vital comum, não pode ser considerada um capital natural associado ao processo de produção, submetido à racionalidade de mercado. Diante disso, o conceito de patrimônio resgata o sentido de um direito natural ao conceder o usufruto para as gerações atuais que reconhecem e preservam o direito das futuras gerações. Supera-se assim, a definição da água como um bem que traz implícito um valor fortemente econômico.

Além disso, a visão patrimonial é consistente com os direitos da natureza, o que significa a defesa desses recursos pelo seu próprio valor, independentemente de sua utilização comercial [...] Desarma-se o conceito de capital hídrico, que é uma forma de delinear a água dentro da lógica mercantil, quer dizer ver a água simplesmente como uma ferramenta do processo produtivo. ${ }^{16}$

- Enquanto componente da natureza, a água é indispensável para a vida. Expressa a possibilidade da existência, da continuidade da vida em nosso planeta. Dessa forma, em consonância com a Ética biocêntrica, a constituição vincula o direito da água ao direito da natureza. Não poderia ser diferente, na medida em que o novo pacto de convivência representa o reconhecimento dos direitos da natureza e a superação da Ética antropocêntrica.

Isso significa criar bases materiais de sobrevivência que respeitem a cultura e promovam o "bem viver", e a dignidade humana seja o referente de uma vida, com qualidade, em permanente construção.

A nova constituição é pioneira em reconhecer direitos à natureza. Existem muitos artigos que estabelecem este direito e que propõem um modelo de desenvolvimento ao país em harmonia com a natureza e o ambiente. Os direitos da natureza estão em íntima relação com a proposta de um novo regime de desenvolvimento, o regime do bem viver ou sumak kawsay. $\mathrm{O}$ bem viver implica harmonia: do ser consigo mesmo, com seus congêneres, com a natureza. Neste sentido tem coerência incorporar a natureza como sujeito de direitos, pois sem ela não é possível a vida dos seres humanos. $\mathrm{A}$ manutenção e regeneração dos ciclos vitais da natureza, entre eles o mais importante, o da água, não implica somente o cuidado e gestão sustentável de ecossistemas fundamentais para a água, senão também o manejo integral da água em seus diversos usos, desde a captação até a descarga, uma vez que a água é utilizada. Isto implica incorporar mudanças profundas no uso e tratamento da água em setores urbanos, na agricultura, na indústria, nas mineradoras, na indústria petroleira. ${ }^{17}$

${ }^{15}$ Op. cit., p.26-27.

${ }^{16}$ ACOSTA, Alberto; MARTíNEZ Esperanza. Op. cit., p.27.

${ }^{17}$ Op. cit., p. 37

R. Inter. Interdisc. INTERthesis, Florianópolis, v.9, n.1, p. 51-69, Jan./Jul. 2012 
Sendo assim, com a Constituição do Equador de 2008, a água passa a ser compreendida como um patrimônio de todos os seres vivos, e sua gestão deve ser público-comunitária. O texto constitucional relaciona a água com todos os direitos humanos, e também com os direitos da natureza. Certamente, o direito à água é visto como um direito natural, portanto, "como todo direito natural, os direitos sobre a água constituem um direito de usufruto; as águas podem ser utilizadas, mas não pertencem a ninguém". ${ }^{18}$ Nesse sentido, a Constituição proíbe a privatização, pois a água pertence a todos. Nos países andinos, ela é um ser vivo que permite a continuidade da vida. O ciclo da água integra os seres vivos à natureza, e interage em todos os ecossistemas, permitindo a articulação entre a natureza e as sociedades com diferentes formas de desenvolvimento.

Os representantes oficiais dos países andinos, notadamente da Bolívia, como porta vozes dessa cultura, buscam a universalização desses referentes no âmbito internacional, senão vejamos:

El 22 de abril del 2009, la Organización de Naciones Unidas (ONU) acogió
la iniciativa impulsada por la delegación boliviana y declaró a esta fecha el
día internacional de la Madre Tierra, proyectando una nueva conciencia de
que no es un planeta solamente, mucho menos materia inerte: es nuestra
Madre Tierra (Pachamama). Así se abre una puerta para dejar de hablar de
"explotación de recursos" y emerger en el respeto a todo lo que nos da vida
y permite el equilibrio natural de todas las formas de existencia para vivir
bien. El siguiente paso será promulgar la declaración de los derechos de la
Madre Tierra y hacerla vinculante para todos los países. ${ }^{19}$

Apesar dos avanços obtidos, com o Comentário Geral nำ15 (ONU, 2002), sem dúvida o reconhecimento mais significativo em relação ao direito humano à água no âmbito das Nações Unidas ocorreu na Assembleia Geral, com a Resolução no 64/292, em 2010, encaminhada pelo Embaixador da Bolívia, afirmando explicitamente o direito humano à água e ao saneamento, destacando que a sua efetivação é essencial para a realização de todos os direitos humanos. Essa resolução exorta aos Estados e às organizações internacionais a disponibilizarem recursos financeiros, com transferência de tecnologia, por meio de assistência e cooperação internacionais, prioritariamente aos países em desenvolvimento. Efetivamente, com essa Resolução, a Assembleia Geral das Nações Unidas reconheceu o direito humano à água potável e ao saneamento como fundamental

\footnotetext{
${ }^{18}$ ACOSTA, Alberto; MARTÍNEZ Esperanza. Op. cit., p.262

19 Op. cit., p.09
}

R. Inter. Interdisc. INTERthesis, Florianópolis, v.9, n.1, p. 51-69, Jan./Jul. 2012 
para a realização integral do direito à vida ${ }^{20}$.

Posteriormente, o Conselho de Direitos Humanos das Nações Unidas aprovou a Resolução n. 15/9, de 30 de setembro de 2010, acolhendo o reconhecimento do direito humano à água e ao saneamento da Resolução $\mathrm{n}^{0}$ 64/292, afirmando que ambos resultam do direito a um nível de vida adequado e estão "indissoluvelmente associados ao direito ao mais alto nível possível de saúde física e mental, assim como ao direito à vida e dignidade humana". Concretamente, as duas resoluções implicam um grande avanço na luta internacional, bem como são um marco contundente na luta pela justiça da água. Uma vez destacados alguns elementos fundantes de natureza jurídica na nova cosmovisão andina, particularmente proveniente do constitucionalismo equatoriano, cabe, a seguir, ampliar o campo de análise de Direito como Direito humano aos recursos enquanto patrimônio comum.

\section{ASPECTOS DO “NOVO" DIREITO AOS RECURSOS NATURAIS NOS HORIZONTES LATINO-AMERICANOS}

Parece evidente que as mudanças políticas e os novos processos sociais de luta nos Estados latino-americanos engendram não só novas constituições que materializam novos atores sociais, realidades plurais e práticas biocêntricas desafiadoras, mas, igualmente, propõem, diante da diversidade de culturas minoritárias, da força inconteste dos povos indígenas do Continente, de políticas de desenvolvimento sustentável e da proteção de recursos comuns naturais, um novo paradigma de constitucionalismo ${ }^{21}$, o qual poderia denominar-se de Constitucionalismo Pluralista - síntese de um Constitucionalismo indígena, autóctone e mestiço.

Possivelmente, a etapa primeira e de grande impacto para este novo constitucionalismo latino-americano vem a ser representada pela Constituição do Equador de 2008 (como já foi mencionado no item anterior), por seu arrojado "giro

${ }^{20}$ BARLOW, Maude. Água Pacto Azul. A crise global da água e a batalha pelo controle da água potável no mundo. São Paulo: M.Books, 2009. p. 4.

${ }^{21}$ Pautas para o workshop El (Neo) Constitucionalismo Multicultural en América latina. Daniel Bonilla Maldonado e Pavel H. Valer-Belloto. Oñati (España), 7-8 de mayo de 2009.

R. Inter. Interdisc. INTERthesis, Florianópolis, v.9, n.1, p. 51-69, Jan./Jul. 2012 
biocêntrico", admitindo direitos próprios da natureza e direitos ao desenvolvimento do "bem viver". A inovação desses direitos vinculados à natureza não impede de se reconhecer os avanços gerais e o enriquecimento dos direitos coletivos como "direitos das comunidades, povos e nacionalidades", destacando a ampliação de seus sujeitos, dentre as nacionalidades indígenas, os afro-equatorianos, os comunais e os povos costeiros (arts. 56 e 57 ).

Naturalmente, os temas de maior impacto estão presentes nos capítulos sétimo do título II, sobre os princípios (arts. 12-34) e o regime dos direitos do "bem viver" (arts. 340-394), bem como sobre dispositivos acerca da "biodiversidade e recursos naturais" (arts. 395-415), ou seja, sobre o que vêm a ser os denominados "direitos da natureza". Matéria de controvérsia, repercussão e de novas perspectivas, a Constituição Equatoriana rompe com a tradição constitucional clássica do Ocidente, que atribui aos seres humanos a fonte exclusiva de direitos subjetivos e direitos fundamentais, para introduzir a natureza como sujeito de direitos. Trata-se da ruptura e do deslocamento de valores antropocêntricos (tradição cultural europeia) para o reconhecimento de direitos próprios da natureza, um autêntico "giro biocêntrico", fundado nas cosmovisões dos povos indígenas. Assim, ao reconhecer direitos da natureza, sem sujeitos da modernidade jurídica e independentemente de valorações humanas, a Constituição de 2008 se propõe a realizar "uma mudança radical em comparação aos demais regimes constitucionais na América latina". ${ }^{22}$

Considerado como a pedra angular de todo o projeto constitucional equatoriano, no dizer de Rubén Martínez Dalmau, ${ }^{23}$ o conceito de "bien vivir" (que aparece no capítulo sobre biodiversidade e recursos naturais), tradução literal do quéchua "Sumak Kawsay", significa boa vida, proveniente e sintonizado

com as culturas indígenas andinas da América do Sul e é acolhido pelo Equador. É colocado como uma cosmovisão de harmonia das comunidades humanas com a natureza, no qual o ser humano é parte de uma

${ }^{22}$ GUDYNAS, Eduardo. EI Mandato Ecológico. Derechos de la Naturaleza y Políticas ambientales en la Nueva Constitución. Quito: Ediciones Abya-Yala, 2009. p. 30-31, 37; CARBONELL, Miguel. Los Retos del Constitucionalismo en el Siglo XXI. In: CORTE CONSTITUCIONAL DEL ECUADOR para el período de transición. EI Nuevo Constitucionalismo en América Latina. Quito, 2010. p. 51.

${ }^{23}$ MARTÍNEZ DALMAU, Rubén. "EI Nuevo Constitucionalismo Latinoamericano y el proyecto de Constitución de Ecuador de 2008". In: Alter Justitia. Estudio sobre Teoría y Justicia Constitucional.Guayaquil: Universidad de Gayaquil/ Facultad de Jurisprudencia. № 01, 2008. p.24-25.

R. Inter. Interdisc. INTERthesis, Florianópolis, v.9, n.1, p. 51-69, Jan./Jul. 2012 
comunidade de pessoas que, por sua vez, é um elemento constituinte da mesma Pachamama, ou 'Madre Tierra'24

Portanto, trata-se de visualizar a natureza não como uma coisa ou objeto, mas como um "espacio de vida." 25

Certamente que o conceito "postcapitalista" do "bien vivir" expressa uma visão integral da convivência humana e social com a natureza, da justiça com o meioambiente, não podendo haver direitos do bem viver sem uma natureza (Pachamama) protegida e conservada. ${ }^{26}$ Porém, há de se ter presente, como adverte o uruguaio Gudynas, que acompanhou o processo constituinte, que

as tradições culturais andinas expressadas no 'bien vivir' (ou Pachamama) têm muitas ressonâncias com as ideias ocidentais da ética ambiental, promovida, por exemplo, pela 'ecologia profunda' ou os defensores de uma 'comunidade de vida'. (...) Igualmente, nem todas as posturas dos povos indígenas originários são biocêntricas, e inclusive existem diferentes construções para a Pachamama. ${ }^{27}$

Assim, em um contexto muito próximo às propostas do desenvolvimento sustentável e do ambiente ecologicamente equilibrado, a Constituição Equatoriana faz referência muito clara à concreta realização dos bens comuns (água, alimentação, ambiente sadio, cultura, educação, habitat, moradia, saúde, trabalho e segurança) como bens essenciais à vida e ao "bem viver" em harmonia com a natureza. Daí decorre o Direito ao acesso à água "como fundamental e irrenunciável" (art. 12), aos alimentos e ambientes sadios (arts. 13-14), ao habitat e moradia seguros e saudáveis (art. 30), ao Direito à cidade e aos espaços públicos sob os princípios da sustentabilidade (art. 31) e o Direito à saúde (art. 32). Tais benefícios determinam "obrigações tanto para o Estado como para as pessoas e as coletividades (arts. 277 e 278)". ${ }^{28}$

Um segundo momento desse recente Constitucionalismo na América Latina vem a ser representado pelo Constitucionalismo boliviano de 2009. Mais do que

\footnotetext{
${ }^{24}$ QUIROLA SUÁREZ, Diana. "Sumak Kawsay. Hacia un nuevo Pacto Social en Armonía con la Naturaleza". In: ACOSTA, Alberto y MARTíNEZ, Esperanza (Comps.). El Buen Vivir: una vía para el desarrollo. Quito: Ediciones Abya-Yala, 2009. p. 104-105.

${ }^{25}$ QUINTERO, Rafael. "Las Innovaciones conceptuales de la constitución de 2008 y el Sumak Kawsay". In: ACOSTA, Alberto y MARTíNEZ, Esperanza (Comps.).p. 83.

${ }^{26}$ GUDYNAS, Eduardo. Op. Cit., p. 46; BUENDÍA, Fernando. "Regimen del Buen Vivir, Autonomía y Descentralización." In: La Tendencia. Rev. de Analísis Político. Quito: $n^{\circ} 09$, mar/abr 2009. p. 121.

${ }^{27}$ GUDYNAS, Eduardo.op.cit., 36 e 119. Vide ainda: MARTíNEZ DALMAU, Rubén. "EI Constitucionalismo Latinoamericano y El Proyecto de Constitución de Ecuador de 2008", op.cit.,p.2425: WILHELM, Marco Aparicio. "Possibilidades e Limites do Constitucionalismo Pluralista. Direitos e Sujeitos na Constituição Equatoriana de 2008”. In: VERDUM, Ricardo (Org.). op.cit., p.144-146.

${ }^{28}$ CF. Constitución de la República Del Ecuador. Asamblea Nacional. 2008.
}

R. Inter. Interdisc. INTERthesis, Florianópolis, v.9, n.1, p. 51-69, Jan./Jul. 2012 
perfilar no âmbito do que se pode denominar de um Constitucionalismo andino, trata-se de um novo Direito de tipo comunitário plurinacional e descolonial. Nesse sentido, assinala Bartolomé Clavero que a

Constituição de Bolívia de 2009 é a primeira Constituição das Américas que estabelece as bases para o acesso a direitos e poderes de todos, adotando uma posição íntegra e congruentemente anticolonialista, a primeira que rompe de uma forma decidida com o trato tipicamente americano do colonialismo constitucional ou constitucionalismo colonial desde os tempos da independência. ${ }^{29}$

É a "refundação" do Estado boliviano, marcadamente indígena, anticolonialista e plurinacional.

Mais claramente, no que se refere ao Direito aos recursos naturais como patrimônio comum, a Constituição de 2009 reconheceu sua relevância, bem como sua necessária proteção e preservação. Primeiramente, dispõe no capítulo dos Direitos sociais e econômicos, o Direito ao meio-ambiente saudável e equilibrado (art. 33), o Direito à saúde, à segurança social e ao trabalho (arts. 35 e 46). Já os recursos patrimoniais comuns naturais do meio-ambiente (art. 342), das florestas, do subsolo, da biodiversidade (art. 348, 380), dos recursos hídricos (art. 373) e da terra (art. 393), são merecedores de conservação, proteção e regulamentação por parte do Estado e da população. Significativo também é a chamada de atenção para as coletividades presentes e futuras, acerca da proteção especial do espaço estratégico, representado pela Amazônia boliviana (art. 390-392) e o fortalecimento de políticas ao desenvolvimento rural integral sustentável (arts. 405-409).

Adota a Constituição boliviana as mesmas medidas de reconhecimento, defesa e manejo sustentável dos recursos hídricos, que não podem ser objeto de apropriação privada (art. 374). Possivelmente, seja o capítulo dedicado aos recursos hídricos (IV Parte, Título II), um dos que melhor foi contemplado na cosmovisão ambiental pelo constituinte boliviano. Por sua vez, fica enfatizado - dentre os principais "bens comuns" - o uso prioritário da água para vida. Por sinal, pelo impacto e desafios que se abrem, um dos pontos significativos e desafiadores para 0 novo Constitucionalismo latino-americano: o Direito da natureza e o Direito ao acesso à água. Neste escopo, a água constitui, como dispõe a Constituição, em seu art. 373, "um Direito fundamental para a vida, nos marcos da soberania do povo. 0

29 CLAVERO, Bartolomé. Bolívia entre Constitucionalismo colonial y Constitucionalismo emancipatório. Texto inédito, s/ed., maio de 2009. p. 02

R. Inter. Interdisc. INTERthesis, Florianópolis, v.9, n.1, p. 51-69, Jan./Jul. 2012 
Estado promoverá o uso e o acesso à água sobre a base de princípios da solidariedade, (...) reciprocidade, equidade, diversidade e sustentabilidade".

\section{CONCLUSÃO}

O novo Constitucionalismo - Constitucionalismo de tipo pluralista - que se instaurou na América Latina a partir de mudanças políticas e novos processos sociais de lutas na região, nas duas últimas décadas, tem, principalmente nas Constituições do Equador (2008) e da Bolívia (2009), o espaço estratégico de inspiração e legitimação para impulsionar o desenvolvimento de paradigmas de vanguarda no âmbito das novas sociabilidades coletivas (povos originários, indígenas e afrodescendentes) e dos Direitos ao patrimônio comum (recursos naturais e ecossistema equilibrado) e culturais (Estado pluricultural, diversidade e interculturalidade).

Assim, o desenvolvimento de alguns desses grandes eixos norteadores, já previstos e consagrados no novo Constitucionalismo Pluralista da América andina, implica em desafios de assimilar e de interagir na direção de sua real materialização. O desafio para o futuro da região está na concretização efetiva e complexa de novos paradigmas epistêmicos concebidos e projetados, que vão muito além do institucionalizado e do normatizado juridicamente. $O$ desafio para continentes como a América Latina está em encontrar pontos hermenêuticos de convergência e complementaridade com o "sistema-mundo", sem perder sua identidade autóctone e mestiça. Como transformar-se no cenário natural e cultural da pluralidade, insurgência e criatividade enquanto simbiose planetária da vida humana e do ecossistema? A resposta, quem sabe, pode ser encontrada nos horizontes da complexidade e da solidariedade. Uma cosmovisão marcada por solidariedade mais ampla e flexível, das coletividades presentes e futuras, no sentido de preservar não só os recursos comuns naturais (água como bem supremo e patrimônio da humanidade), mas de sociabilizar e resolver os problemas sociais e culturais comuns de todos no futuro. 


\section{REFERÊNCIAS}

ACOSTA, Alberto; MARTÍNEZ, Esperanza. Agua: Un derecho humano fundamental. Quito: Abya Yala, 2010. p.18-23.

BARLOW, Maude. Água Pacto Azul. A crise global da água e a batalha pelo controle da água potável no mundo. São Paulo: M.Books, 2009.

BONILLA MALDONADO, Daniel. La Constitución Multicultural. Bogota: Siglo del Hombre; Pont.Universidad Javeriana; Universidad de los Andes, 2006.

BUENDÍA, Fernando. Regimen del Buen Vivir, Autonomía y Descentralización. La Tendencia. - Rev. de Análisis Politico, Quito, n. 9, mar./abr. 2009.

CARBONELL, Miguel; OROZCO, Wistano; VAZQUEZ, Rodolfo (Org.). Estado de Derecho. Concepto, fundamentos y democratización en América Latina. México: Siglo Veintiuno, 2002.

CARBONELL, Miguel; OROZCO, Wistano; VAZQUEZ, Rodolfo (Org.). Los Retos del Constitucionalismo en el Siglo XXI. In: CORTE CONSTITUCIONAL DEL ECUADOR. EI Nuevo Constitucionalismo en América latina. Quito, 2010.

ECUADOR. Constitución de la República Del Ecuador. Asamblea Nacional, 2008.

CLAVERO, Bartolomé de. Bolívia entre constitucionalismo colonial y constitucionalismo emancipatorio. Maio de 2009.

DE LA TORRE RANGEL, Jesús Antonio. Sociologia jurídica y uso alternativo del derecho. México: Instituto Cultural de Aguascalientes, 1997.

GUDYNAS, Eduardo. El mandato Ecológico. Derechos de la Naturaleza y Políticas Ambientales en la Nueva Constitución. Quito: Ediciones: Abya-Yala, 2009.

MAMANI, Fernando Huanacuni. Buen Vivir / Vivir Bien: filosofía, políticas, estrategias y experiencias regionales andinas. Lima, 2010.

MAMANI, Fernando Huanacuni. EI Nuevo Constitucionalismo Latinoamericano y el proyecto de Constitución de Ecuador de 2008. Alter Justitia, n. 1, 2008.

QUIROLA SUÁREZ, Diana. Sumak Kawsay. Hacia un Nuevo Pacto Social en Armonía con la Naturaleza. In: ACOSTA, Alberto; MARTíNEZ, Esperanza (Comps.). El Buen Vivir: una via para el desarrollo. Quito: Abya-Yala, 2009.

QUINTERO, Rafael. Las Innovaciones conceptuales de la constitución de 2008 y el Sumak Kawsay. In: ACOSTA, Alberto; MARTÍNEZ, Esperanza. Agua: Un derecho humano fundamental. Quito: Abya Yala, 2010. p. 83.

VERDUM, Ricardo (Org.). Povos indígenas: constituição e reformas políticas na América Latina. Brasília: Instituto de Estudos Socioeconômicos, 2009. 
WIARDA, Howard J. O modelo corporativo na América Latina e a Latinoamericanização dos Estados Unidos. Petrópolis: Vozes, 1983.

WIARDA, Howard J. Sínteses de uma historia das idéias jurídicas: da Antiguidade clássica à Modernidade. Florianópolis: Fundação Boiteux, 2006.

WIARDA, Howard J. FAGUNDEZ, Lucas Machado. Tendências Contemporâneas do Constitucionalismo Latino-americano: Estado plurinacional e pluralismo jurídico. Pensar - Revista de Ciências Jurídicas, Fortaleza, v.16, n. 2, p. 371-408, jul./dez. 2011.

\section{Dossiê:}

Recebido em: 13/06/2012

Aceito em: 16/07/2012 